\title{
Ausschreibung für den Wettbewerb um die Carl-Diem-Plakette 1985/86
}

1. Der Deutsche Sportbund verleiht alle zwei Jahre für eine hervorragende sportwissenschaftliche Arbeit in deutscher Sprache die Carl-Diem-Plakette. Die Arbeit darf bis zum Abschluß des Wettbewerbs (mit der Festakademie 1986) in der eingereichten Form noch nicht veröffentlicht sein. Der Wettbewerb soll vor allem der Förderung des sportwissenschaftlichen Nachwuchses dienen.

2. Wichtige Kriterien für die Beurteilung der eingereichten Arbeiten sind ihr wissenschaftlicher Charakter, die neuen Erkenntnisse der vorgelegten Untersuchung sowie ihre Originalität und Aktualität.

3. Die Plakette wird in zwei Sektionen (Naturwissenschaften/Medizin und Geistes-/ Sozialwissenschaften) vergeben.

4. Mit der Verleihung der Carl-Diem-Plakette (Erster Preis) sind ein Geldpreis bis zur Höhe von DM 5000.- und eine Urkunde verbunden. Neben dem Ersten Preis können Zweite Preise vergeben und Lobende Anerkennung ausgesprochen werden.

5. Einsendeschluß für die in sechsfacher Ausfertigung als Einschreibsendung an den Deutschen Sportbund, Otto-Fledk-Schneise 12, 6000 Frankfurt am Main 71, zu richtenden Arbeiten ist der 31. März 1986 (Poststempel). Später eingereichte Arbeiten können nicht berücksichtigt werden.

6. Von den mit der Carl-Diem-Plakette oder mit anderen Preisen ausgezeichneten Arbeiten gehen die eingereichten sechs Belegstücke in das Eigentum des Deutschen Sportbundes über. Von allen anderen Arbeiten verbleiben zwei Belegstüdke als Archivexemplare beim Deutschen Sportbund.

7. Eine mit der Plakette oder mit einem anderen Preis ausgezeichnete Arbeit kann nach Entscheidung des Kuratoriums im Rahmen der "Wissenschaftlichen Schriftenreihe des Deutschen Sportbundes" veröffentlicht werden.

8. Der eingereichten Arbeit sind folgende Angaben beizufügen:

a) Name, Anschrift und kurz gefaßter Lebenslauf des Verfassers;

b) eine eidesstattliche Erklärung, daß die Arbeit selbständig vom Verfasser angefertigt worden ist und daß die Bewerbung den Bedingungen der Ausschreibung gerecht wird;

c) eine vollständige Zusammenstellung der benutzten Hilfsmittel und die Versicherung, daß keine anderen Hilfsmittel benutzt worden sind (soweit diese Angaben nicht bereits in der Arbeit selbst enthalten sind);

d) eine Erklärung, ob, wo und in welcher Fassung die Arbeit bereits Gegenstand eines Wettbewerbs war oder ist.

9. Die Preisträger werden in einer Festakademie, die gewöhnlich gegen Ende des zweiten Wettbewerbsjahres abgehalten wird, geehrt.

Frankfurt am Main, im Juli 1985

KURATORIUM FUR DIE VERLEIHUNG DER CARL-DIEM-PLAKETTE gez. Professor Dr. Ommo Grupe 